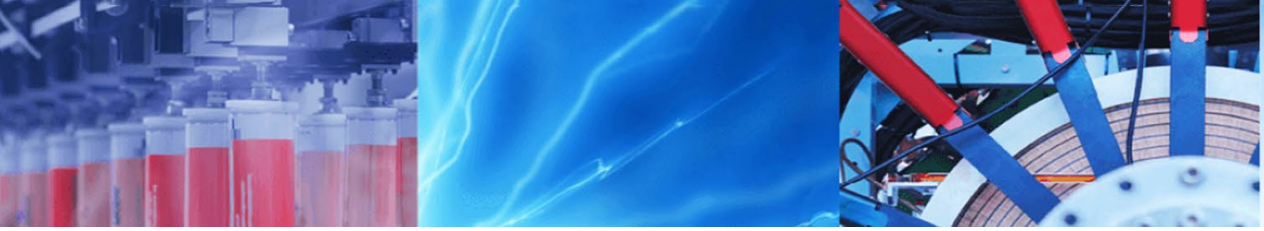

Research Article

\title{
The effect of nanoparticle-added solid lubricant on the formability of sheet metal
}

\author{
Fevzi Şahin ${ }^{1} \cdot$ Cengiz Görkem Dengiz ${ }^{1}$ (1) $\cdot$ Kemal Yıldızlı ${ }^{1} \cdot$ Lütfü Namlı $^{1}$
}

(c) Springer Nature Switzerland AG 2019

\begin{abstract}
In sheet metal forming processes, formation without fracture is related to sheet metal formability. Parameters such as tool geometry, blank holder force, and lubricant are changed in order to push the formability of material to its maximum capacity. Lubricants play an important role in sheet metal forming processes. Depending on the type of lubricant, the formability of the sheet metal can be increased, the surface quality of the product can be improved, and the tool life can be extended. In this study, nanoparticles were added to solid lubricants, and the effect of nanolubricants on sheet metal formability was investigated with Erichsen test. Test specimens were observed by SEM, and the nanoparticle effect was investigated by EDX mapping. In addition, the optimum nanoparticle concentration was determined, and the effects of the nanoparticle on solid lubricants were compared with other lubricants which were used in sheet metal forming. As a result of the study, it was observed that the nanoparticle additive increased the formability by $13 \%$. Results showed that the formability of the sheet metal increased up to certain nanoparticle concentrations, but it decreased above this limit.
\end{abstract}

Keywords Sheet metal forming $\cdot$ Nanolubricant $\cdot \mathrm{SiO}_{2}$ nanoparticle $\cdot$ Deep drawing

\section{Introduction}

Sheet metal forming processes such as deep drawing, spinning, and hydroforming are the preferred methods for producing sheet metal products for reasons such as high efficiency, low cost, standard tolerances, and mass production. The quality of the products manufactured by these methods is directly affected by the type of lubrication and lubricant. In addition, lubricants affect the formability of sheet metal and the fracture that occurs during forming $[1,2]$.

Lubricants used in sheet metal forming processes play an important role in reducing friction, prolonging tool life by reducing wear, increasing the surface quality of the product and increasing formability of sheet metal. Therefore, the determination and improvement of lubrication properties of lubricants are important for the future of sheet metal forming processes. There are many studies in the literature on lubricants used in forming processes. Mosleh et al. examined the tribological properties of forming fluid by adding different nanoparticles such as $\mathrm{MoS}_{2}, \mathrm{WS}_{2}$, and $\mathrm{hBN}$ at different ratios [3]. They determined that nanoparticles of $50-100 \mathrm{~nm}$ in size exhibited significant resistance to wear. They also showed that the nanoparticle concentration increased the rate of wear when it exceeded a certain limit. In another study, Zareh-Desari and Davoodi added CuO and $\mathrm{SiO}_{2}$ nanoparticles to soy and canola oils and examined the effect of these oils on forming processes by performing a standard ring compression test [1]. They observed that the $\mathrm{SiO}_{2}$-added vegetable oil reduced friction. They also showed that the total amount of energy consumed decreased in the forming process using the nanoparticle-added oil. Li et al. [4] conducted an extensive literature review on the friction that occurs in sheet metal forming processes and the factors of friction. In this study, it was emphasized again that the

Cengiz Görkem Dengiz, gorkem.dengiz@omu.edu.tr| 'Department of Mechanical Engineering, Engineering Faculty, Ondokuz Mayıs University, 55200 Atakum, Samsun, Turkey.

SN Applied Sciences (2019) 1:384 | https://doi.org/10.1007/s42452-019-0416-5

Received: 11 January 2019 / Accepted: 26 March 2019 / Published online: 2 April 2019 
lubricant was an effective factor in reducing the heat and friction generated during the forming process.

The interactions of nanoparticle-added lubricants (nanolubricants) with the surface during lubrication and the change in lubricant performance have been studied by many researchers. On this subject, Gulzar et al. [5] prepared a large-scale literature review that examined the tribological properties of nanoparticles added to lubricants. In this review, the effect of nanoparticles on lubricity was revealed by four different lubrication mechanisms such as a ball bearing effect [6-8], protective film formation [9-11], mending effect [12], and polishing effect [13].

In the literature, various tests have been used to determine the properties and effects of lubricants used in forming processes. Cora et al. [6] conducted a sliding friction test to determine the friction characteristics of coatings on molds. Herrmann et al. [7] determined the cooling and lubrication properties of vegetable oils using the grinding test. Abdullah et al. [8] determined the properties of nanoparticle-added lubricants under high pressure using the four-ball method. In addition, methods such as ring compression $[17,18]$ and pin on disk $[5,19]$ were used to determine the friction coefficient and lubricant effect in forming processes. In sheet metal forming processes, tests such as the deep drawing test, Erichsen test, and Nakazima test were generally carried out under lubricated and dry conditions, and the effect of lubricants on the formability of sheet metal was investigated [9-12].

Although there were many studies in the literature on nanoparticle-added lubricants and the processes used for these lubricants, a few studies can be found that examine the effects of nanoparticle-added lubricants on sheet metal forming processes. In this study, the effect of silicon dioxide $\left(\mathrm{SiO}_{2}\right)$ nanoparticles on the sheet metal forming process when added to vegetable solid lubricant was investigated. In the first stage, the solid lubricant is melted, and $\mathrm{SiO}_{2}$ nanoparticles are added and cooled. This lubricant was then applied to the sheet metal sample surfaces, and the sheet metal samples were subjected to the Erichsen test. Then, the best nanoparticle concentration was determined by comparing the deformation depths obtained from the experiment. In addition, the commercial lubricants used in the market were compared with the nanolubricant to find out which one reached the highest deformation depth. The surfaces of the samples subjected to the Erichsen test were imaged by SEM and analyzed for base lubricant and nanoparticle residues by EDX analysis.

\section{Experimental procedure}

\subsection{Materials}

In the tests, DC01 low-carbon cold-rolled steel sheet, which is commonly used in deep drawing processes, was examined for its formability with base lubricant, nanolubricant, and in dry conditions. The mechanical and surface properties of the used steel sheet are given in Table 1.

\subsection{Erichsen test}

The Erichsen test is a simple and fast method that is often used to determine and compare sheet metal formability. In this method, the sheet metal is clamped between the blank holder and the die is stretched with a spherical punch until a fracture occurs. The maximum dome height obtained before the fracture is considered a measure of formability. The dome height could vary depending on the blank holder force (BHF) and the lubrication condition. The Erichsen test setup used in this study had a loading capacity of $20 \mathrm{kN}$. Figure 1 shows the dimensions of the die set used in this test.

The sheet metal with $60 \times 60 \mathrm{~mm}^{2}$ dimensions was clamped between the blank holder, and the die and the BHF were applied with bolts. In all experiments, the bolts were tightened using a torque meter with a torque of $50 \mathrm{Nm}$ to apply the same BHF. Since the BHF was sufficient, the sample measurements did not change at the end of the test. The lubricants used in the tests were applied only to the surface of the punch and to the surface of the sheet metal in contact with the punch, and no lubricant was applied to the sheet metal surfaces between the die and the blank holder. The punch speed was set at $0.5 \mathrm{~mm} / \mathrm{s}$. The applied punch force and deformation depth were measured instantaneously and recorded with a data logger. In addition, the fracture or necking that occurred during the test was instantaneously observed with a mirror in the test setup. All tests were repeated at least three times, and the results were evaluated.

\subsection{Characterization and preparation of nanolubricants}

The formability of the sheet metal used in forming processes and the surface quality of the produced product have significant importance [13]. In order to improve the surface quality of products, the most commonly used method is to apply lubricants on the part and die sets. This method also helps
Table 1 Mechanical and surface properties of DC01

\begin{tabular}{lllllll}
\hline Material & Thickness & Elastic modulus & Yield strength & Tensile strength & Elongation & Mean roughness \\
\hline DC01 & $0.6 \mathrm{~mm}$ & $196.5 \mathrm{GPa}$ & $175.8 \mathrm{MPa}$ & $323.7 \mathrm{MPa}$ & $\% 11.3$ & $1.09 \mu \mathrm{m}$ \\
\hline
\end{tabular}




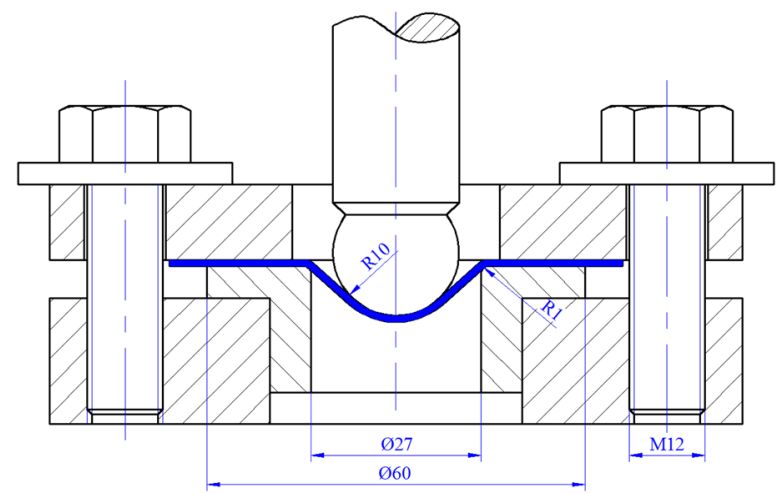

(a)

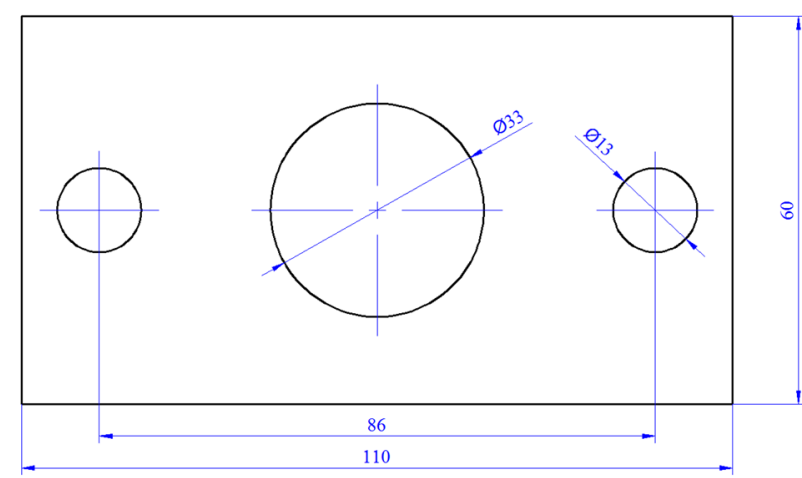

(b)

Fig. 1 a Front view of the Erichsen test setup and $\mathbf{b}$ top view of the blank holder [12]

reduce costs by extending the tool life. However, the lubricants used in the market have some disadvantages such as high cost, difficult cleaning, and being dangerous for health.

In this study, vegetable fat was selected as an alternative to the lubricants used in the market. The reasons for choosing this vegetable fat were as follows:

- It is ensured that vegetable fat can be comfortably applied on sheet metal surfaces.

- Vegetable fat is easier to clean than other mineral or synthetic oils.

- Vegetable fat residues are not a threat to human health and environmental pollution [1].

- Vegetable fat is considerably cheaper than other oils used in sheet metal forming processes, and this helps reduce the costs of the products.

- Inexpensive and easily accessible vegetable oil can be converted into a high added value product.

Eighty-two percent of vegetable fats consist of sunflower oil, soybean oil, cottonseed oil, canola oil, and palm oil at different rates, while the remaining $18 \%$ is composed of milk, milk proteins, water, and other additives. Physical properties of vegetable oils and fatty acid components are given in Table 2.

Due to the unique physical and chemical properties of nanoparticles, they are frequently used in lubricants as additives [16]. In this study, $\mathrm{SiO}_{2}$ nanoparticles were added to a vegetable lubricant. The physical properties of the $\mathrm{SiO}_{2}$ nanoparticles used in the production of the lubricant are given in Table 3. The reasons for the selection of $\mathrm{SiO}_{2}$ nanoparticles in nanolubricant production can be summarized as follows:

- It is desirable that the lubricants designed for use in sheet metal forming operations are inexpensive. $\mathrm{SiO}_{2}$ is abundant in nature, and it is one of the cheapest nanoparticles [1].

- The surface energies of the nanoparticles are high; so they are not easily mixed as in normal solid-liquid mixtures when mixed in fluids. For this reason, certain methods are used to mix the nanoparticles in the fluid. From this point of view, $\mathrm{SiO}_{2}$ nanoparticles are among the most dispersible ones in fluids [17].

- Many studies on nanoparticle-added lubricants showed that $\mathrm{SiO}_{2}$ nanoparticles improve the tribological properties of the base oil [1, 16-18].

The flowchart of the prepared nanolubricants is given in Fig. 2. It is difficult to distribute the $\mathrm{SiO}_{2}$ nanoparticles directly and homogeneously in the oil. Two different methods are found in the literature [19]. In the one-step method, nanoparticles are produced directly in the fluid. In the two-step method, the produced nanoparticles are directly mixed into the fluid, and then, ultrasonic mixing and addition of surfactants are carried out to obtain a homogeneous mixture.

In this study, the two-step method was used to produce nanolubricants. Vegetable fat, as the base lubricant, was liquidized at $80^{\circ} \mathrm{C}$ using a magnetic-heated mixer. The viscosity of the base lubricant was high. The base lubricant was diluted with ethyl alcohol to facilitate the mixing of nanoparticles in the base lubricant and to increase the efficiency of the ultrasonic mixer. First, $\mathrm{SiO}_{2}$ nanoparticles were mixed with ethyl alcohol mechanically and ultrasonically. The resulting homogeneous mixture of $\mathrm{SiO}_{2} /$ ethyl alcohol was added to the base flow at $80^{\circ} \mathrm{C}$. Then, mechanical and ultrasonic mixing operations were applied to the mixture. Finally, the mixture was stirred with a magnetic stirrer at $80^{\circ} \mathrm{C}$ for $3 \mathrm{~h}$ to completely remove the ethyl alcohol from the mixture.

Considering previous researches, it is seen that the tribological properties of nanoparticle-added lubricants depend on nanoparticle size, concentration, shape, and oil stability [5]. In this study, 30-40 nm spherical $\mathrm{SiO}_{2}$ nanoparticles were obtained from the market. The amounts of nanoparticles in 
Table 2 Physical properties and fatty acid components of oils in solid vegetable oil [14, 15]

\begin{tabular}{|c|c|c|c|c|c|}
\hline Properties & Sunflower oil & Soybean oil & Cotton oil & Canola oil & Palm oil \\
\hline Density at $20^{\circ} \mathrm{C}\left(\mathrm{kg} / \mathrm{m}^{3}\right)$ & 914-923 & 919-925 & $918-926$ & $914-920$ & $891-925$ \\
\hline Kinematic viscosity at $40^{\circ} \mathrm{C}(\mathrm{cSt})$ & 33.78 & 31.42 & 40 & 34.06 & - \\
\hline Kinematic viscosity at $100^{\circ} \mathrm{C}$ (cSt) & 7.78 & 7.71 & 37.8 & 7.89 & 47.8 \\
\hline Melt/freeze point temperature $\left({ }^{\circ} \mathrm{C}\right)$ & -17 & -16 & -48 & -10 & 35 \\
\hline Flash point $\left({ }^{\circ} \mathrm{C}\right)$ & 227 & 234 & 225 & 204 & 235 \\
\hline \multicolumn{6}{|l|}{ Fatty acid name } \\
\hline Caproic (C6:0) & - & - & - & - & - \\
\hline Caprylic acid (C8:0) & - & - & - & - & - \\
\hline Capric acid (C10:0) & - & - & - & - & - \\
\hline Lauric acid (C12:0) & $0-0.1$ & $0-0.1$ & $0-0.2$ & - & $0-0.5$ \\
\hline Myristic acid (C 14:0) & $0-1.0$ & $0-0.2$ & $0.6-1.0$ & $0-0.2$ & $0.5-2.0$ \\
\hline Palmitic acid (C 16:0) & $4.0-7.6$ & $8.0-13.5$ & $21.4-26.4$ & $2.5-7.0$ & $39.3-47.5$ \\
\hline Palmitoleic acid (C 16:1) & $0-0.3$ & $0-0.2$ & $0-1.2$ & $0-0.6$ & $0-0.6$ \\
\hline Margaric acid (C 17:0) & $0-0.2$ & $0-0.1$ & $0-0.1$ & $0-0.3$ & $0-0.2$ \\
\hline Heptadecenoic acid (C 17:1) & $0-0.1$ & $0-0.1$ & $0-0.1$ & $0-0.3$ & - \\
\hline Stearic acid (C 18:0) & $2.1-6.5$ & $2.0-5.4$ & $2.1-3.3$ & $0.8-3.0$ & $3.5-6.0$ \\
\hline Oleic acid (C 18:1) & $14.0-71.8$ & $17-30$ & $14.7-21.7$ & $51.0-70.0$ & $36.0-44.0$ \\
\hline Linoleic acid (C 18:2) & $18.7-74.0$ & $48.0-59.0$ & $46.7-58.2$ & $15.0-30.0$ & $9.0-12.0$ \\
\hline Linolenic acid (C 18:3) & $0-0.5$ & $4.5-11.0$ & $0-0.4$ & $5.0-14.0$ & $0-0.5$ \\
\hline Arachidic acid (C 20:0) & $0.1-0.5$ & $0.1-0.6$ & $0.2-0.5$ & $0.2-1.2$ & $0-1.0$ \\
\hline Eicosenoic acid (C 20:1) & $0-0.3$ & $0-0.5$ & $0-0.1$ & $0.1-4.3$ & $0-0.4$ \\
\hline Eicosadienoic acid (C 20:2) & - & $0-0.1$ & $0-0.1$ & $0-0.1$ & - \\
\hline Behenic acid (C 22:0) & $0.3-1.5$ & $0-0.7$ & $0-0.6$ & $0-0.6$ & $0-0.2$ \\
\hline Erucic acid (C 22:1) & $0-0.3$ & $0-0.3$ & $0-0.3$ & $0-2.0$ & - \\
\hline Docosadienoic acid (C 22:1) & $0-0.3$ & - & $0-0.1$ & $0-0.1$ & - \\
\hline Lignoceric acid (C 24:0) & $0-0.5$ & $0-0.5$ & $0-0.1$ & $0-0.3$ & - \\
\hline Nervonic acid (C 24:1) & $0-0.3$ & - & - & $0-0.4$ & - \\
\hline
\end{tabular}

Table 3 Physical properties of silicon dioxide nanoparticles used in nanolubricants

\begin{tabular}{ll}
\hline Properties & \\
\hline Purity $(\%)$ & 99.9 \\
Density $\left(\mathrm{kg} / \mathrm{m}^{3}\right)$ & 2220 \\
Heat transfer coefficient $(\mathrm{W} / \mathrm{mK})$ & 1.4 \\
Specific heat $(\mathrm{J} / \mathrm{kg} \mathrm{K})$ & $745 @ 27^{\circ} \mathrm{C}$ \\
Surface area $\left(\mathrm{m}^{2} / \mathrm{g}\right)$ & $175-225$ \\
Diameter $(\mathrm{nm})$ & $30-40$ \\
Shape & Spherical \\
\hline
\end{tabular}

the nanolubricants were determined by preliminary experiments. As a result of these experiments, the mass nanoparticle ratios were determined as $1,3,5,7.5$, and $10 \mathrm{wt} \%$.

\section{Results and discussion}

\subsection{Effect of nanoparticle concentration and lubricant type}

The deformation depths obtained from the Erichsen test based on the nanoparticle additive ratio are given in Fig. 3. Nanoparticle additions of $1,3,5,7.5$, and $10 \mathrm{wt} \%$ in the lubricant increased deformation depths by $4.72 \%, 9.34 \%$, $11.01 \%, 12.67 \%$, and $10.31 \%$, respectively. The deformation depth values obtained from the experiments with base lubricant were considered as references while these ratios were calculated. The maximum increase in deformation depth was obtained in $7.5 \mathrm{wt} \% \mathrm{SiO}_{2}$-added lubricant. It was observed that the deformation depth started to decrease as the nanoparticle additive ratio was increased over 7.5 wt $\%$.

The formability of the steel sheet tested with nanolubricant showed a remarkable increase. In order to better understand the contribution of this increase to the forming process, it must be compared with the deep drawing oils already used in the industry. Three different deep 
Fig. 2 The flowchart of the nanolubricant preparation

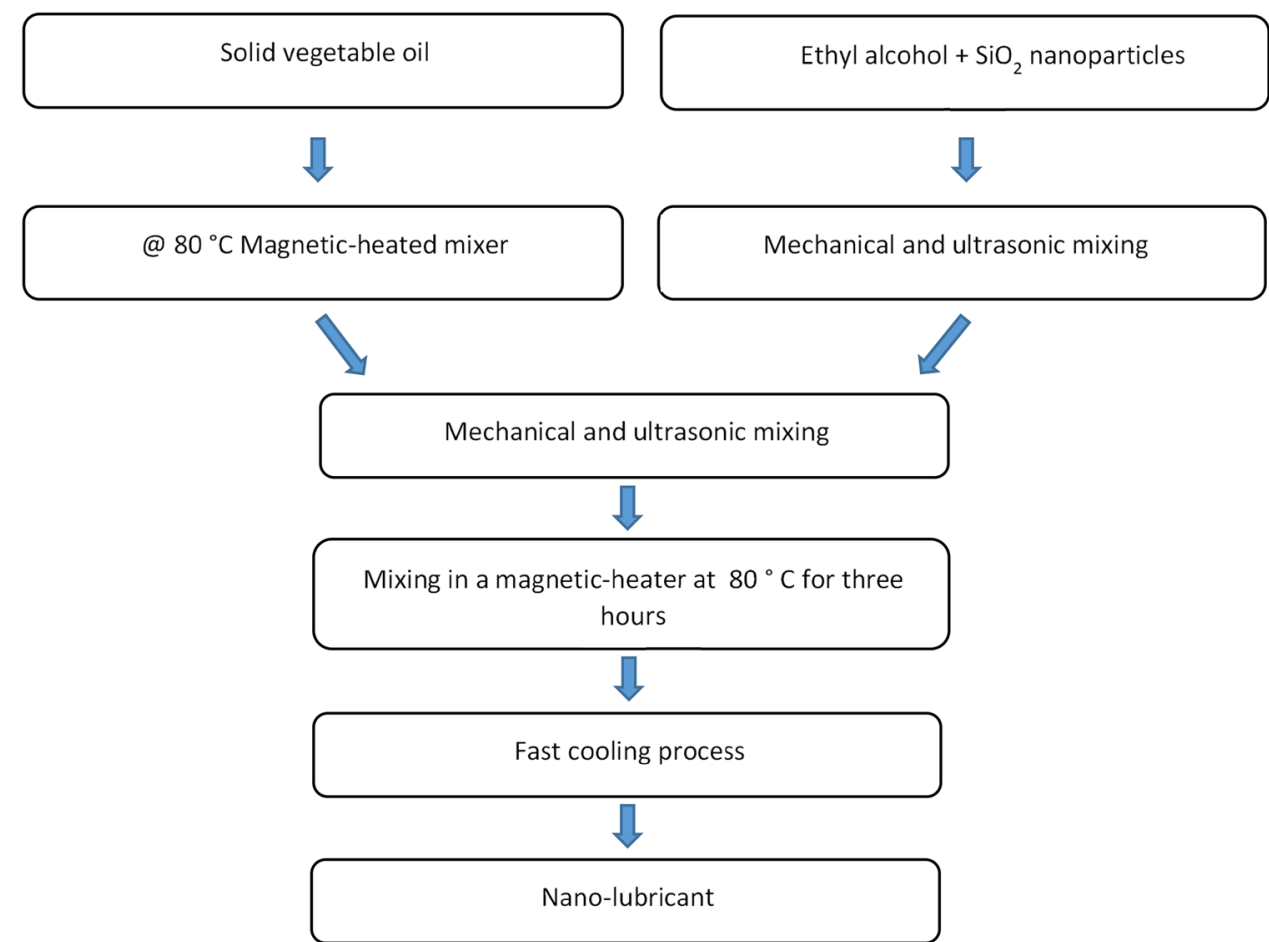

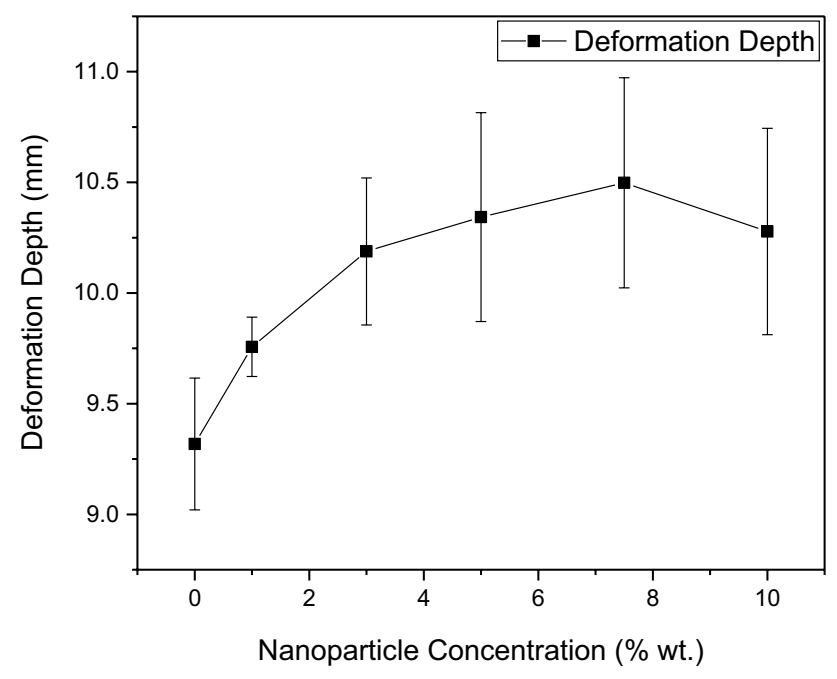

Fig. 3 Deformation depth against the nanoparticle concentration by weight

drawing lubricants, which are frequently used in the industry, were determined for comparison. These lubricants were listed as Oil1, Oil2, and Oil3.

Figure 4 shows the deformation depths of tests using dry conditions (oil-free), base lubricant, nanolubricant, and three different deep drawing oils. Tests using base lubricant showed a limited increase in the formability

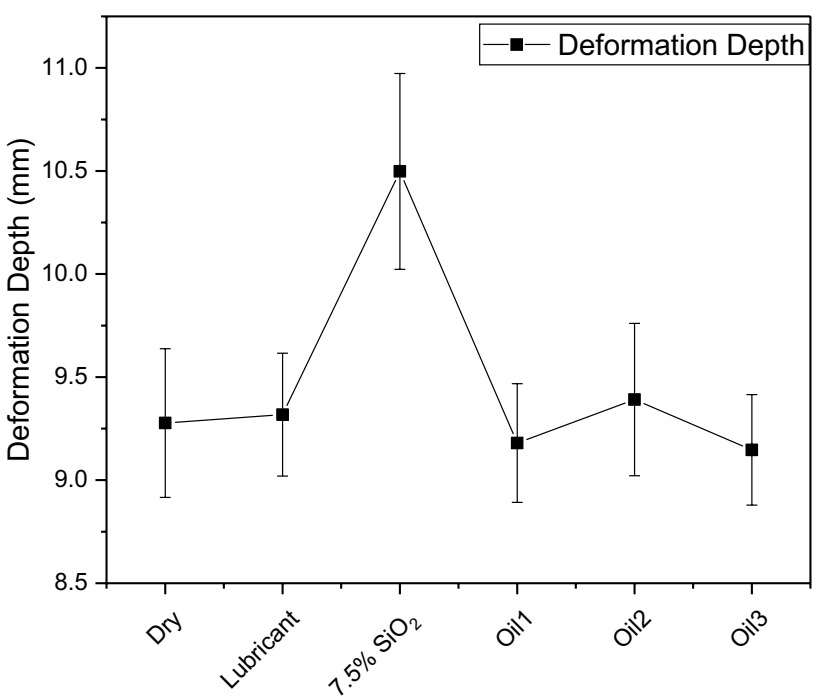

Fig. 4 Comparisons of nanolubricant with dry conditions, base lubricant, and other commercial oils

of the steel sheet. On the other hand, the commercial oils Oil1 and Oil3 did not affect formability, whereas Oil2 increased formability by $1.23 \%$ compared to dry conditions (oil-free). It was observed that the nanolubricant developed by the authors increased the formability by $13.16 \%$ compared to dry conditions. 


\subsection{Deposits of nanoparticles on contact surfaces}

Figure 5a shows an Erichsen-tested sample using $7.5 \mathrm{wt} \%$ $\mathrm{SiO}_{2}$ nanolubricant. Although the punch contact surface of the sheet metal was lubricated before the test, it was observed that there was no visible lubricant layer on the punch contact surfaces after the test. The tearing occurred in the punch contact surface at the end of the test. Samples were taken from the areas where the tear occurred and their surfaces were examined with a scanning electron microscope (SEM). In the randomly selected regions, the surfaces contacting the punch (lighter gray) were distinguished from the traces of friction (Fig. 5b). On the other hand, there were darker gray areas on the sheet where the punch did not contact. When this region was analyzed with energy-dispersive $\mathrm{X}$-ray (EDX) mapping, it was seen that the $\mathrm{Si}$ and $\mathrm{O}$ elements were dense in the darker gray region (Fig. 6a, b). In addition, the $C$ element was also present in this region, as seen in Fig. $6 c$. This indicated the presence of oil in the region.

Figure 7a shows an Erichsen-tested sample using $10 \mathrm{wt} \% \mathrm{SiO}_{2}$ nanolubricant. In this sample, a randomly selected area close to the tearing was also analyzed with SEM. As mentioned before, the punch contact surface of the sheet metal was observed as lighter gray as in Fig. 7b. EDX mapping showed that Si elements in the specimen surface tested with $10 \mathrm{wt} \%$ nanolubricant were found to be denser compared to $7.5 \mathrm{wt} \%$ (Fig. 8a). In the darker gray area, $\mathrm{C}$ and $\mathrm{O}$ elements were observed to be dense because of the lubricant residue (Fig. $8 \mathrm{~b}, \mathrm{c}$ ). In addition, the Fe element was seen in areas where there was no lubricant residue. This result was expected (Fig. $8 \mathrm{~d}$ ).

\subsection{Effect of nanoparticles on formability}

The presence of $\mathrm{SiO}_{2}$ nanoparticles on sheet metal surface was determined by EDX analysis at Figs. 6, 8. The nanoparticles, which are heavily present in the lighter gray regions, created two different situations. In the first situation, the nanoparticles filled the valleys on the sample surface and reduced the abrasion (Fig. 9a, b) [20]. This mechanism is also known as the mending effect in the literature. In addition, the filling of the valleys with nanoparticles delayed the propagation of micro-cracks on the surface of the material [21]. In the second situation, as the nanoparticle concentration in the lubricant exceeded a certain limit, the agglomeration was also increased (Fig. 9c). Some of these agglomerates can be larger than the asperities on the sheet metal surface. However, the agglomerates may also act as an abrasive and reduce the effectiveness of the nanolubricant. This explains the reduction in the formability of the sheet metal when the nanoparticle concentration in the lubricant was at $10 \mathrm{wt} \%$.

\section{Conclusions}

In this study, the aim was to increase the formability of sheet metals used in deep drawing processes by using $\mathrm{SiO}_{2}$ nanoparticle-added lubricant. In the study, $\mathrm{SiO}_{2}$ nanoparticles were added to the organic solid lubricant, and the sheet metals were subjected to the Erichsen test with this lubricant. The results of the study are listed below:

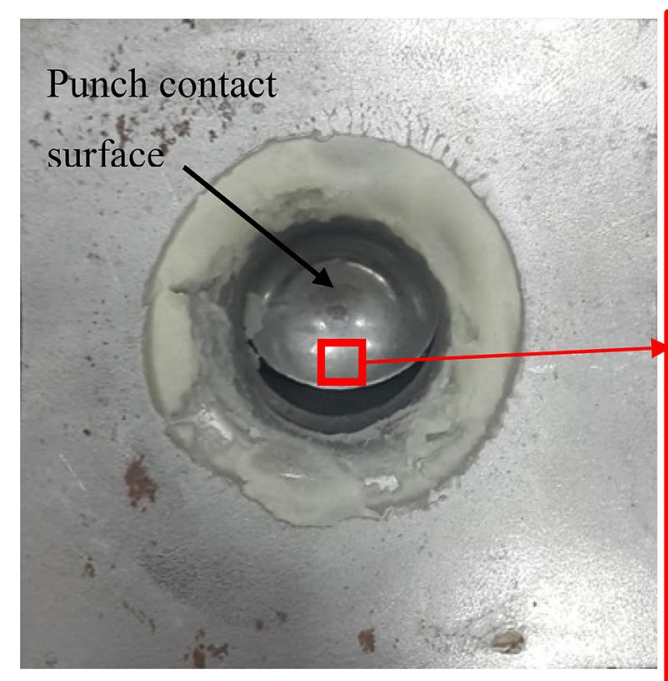

(a)

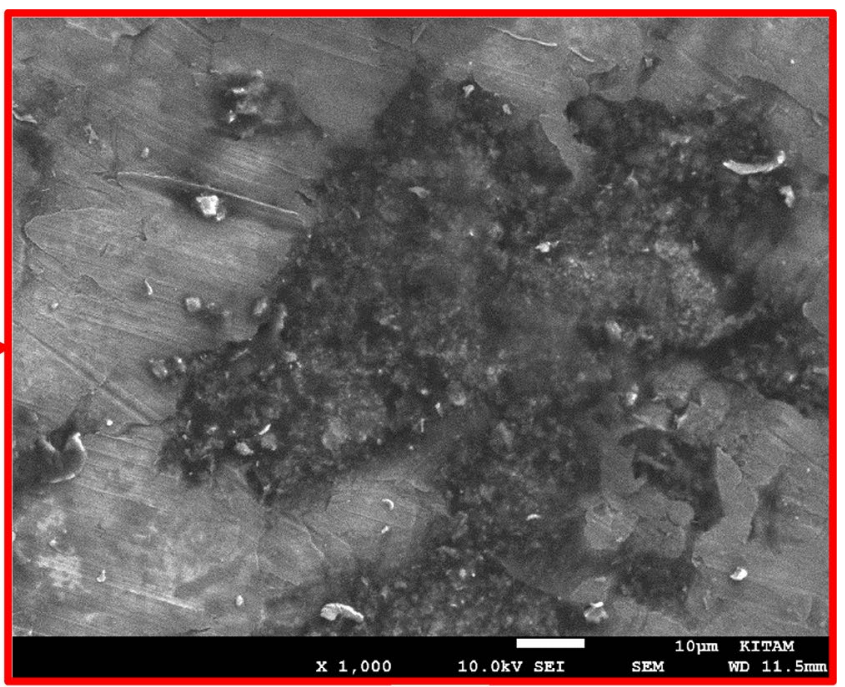

(b)

Fig. 5 a A specimen with 7.5 wt\% $\mathrm{SiO}_{2}$ nanolubricant after the Erichsen test; $\mathbf{b}$ a randomly selected punch-sheet metal contact surface 


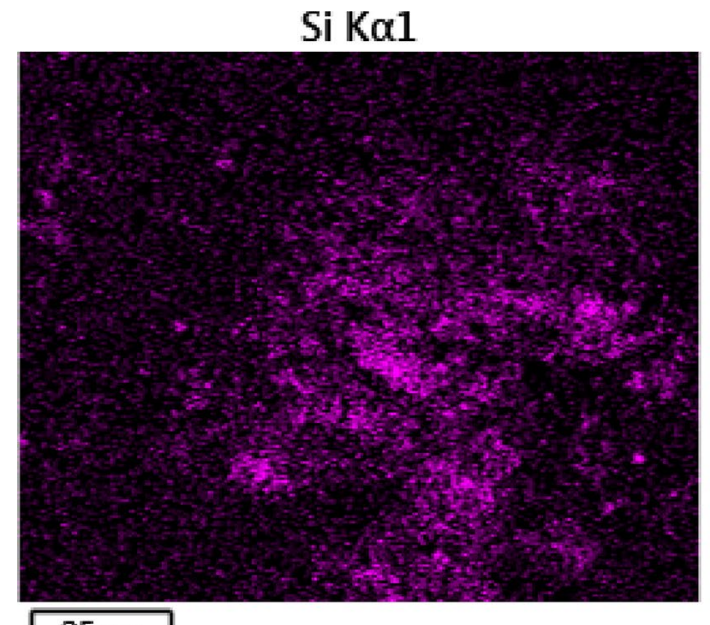

$\longdiv { 2 5 \mu \mathrm { m } } \quad$ (a)

C K $\alpha 1 \_2$

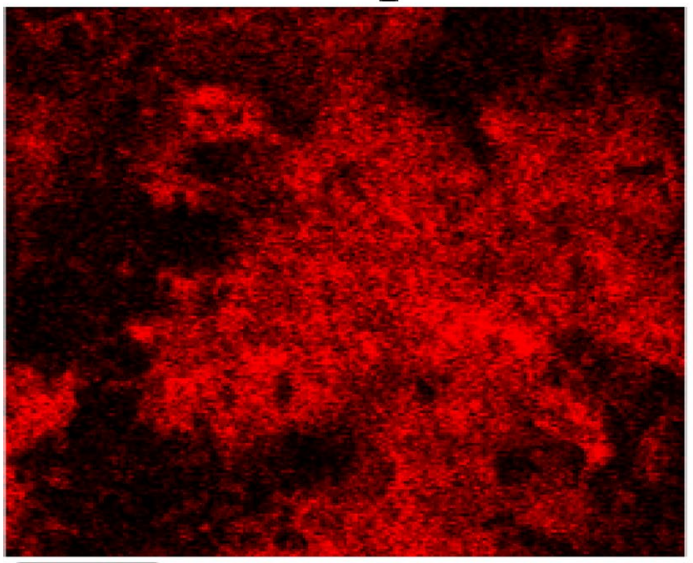

$25 \mu \mathrm{m}$

(c)

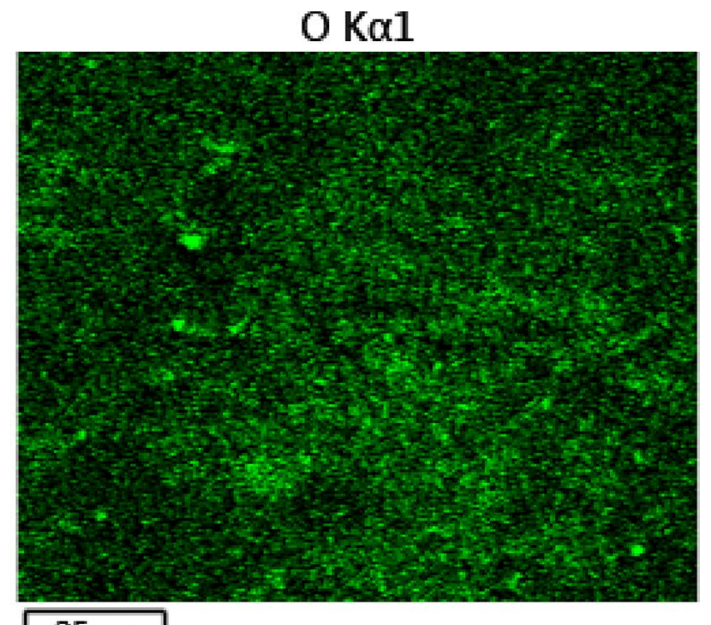

(b)

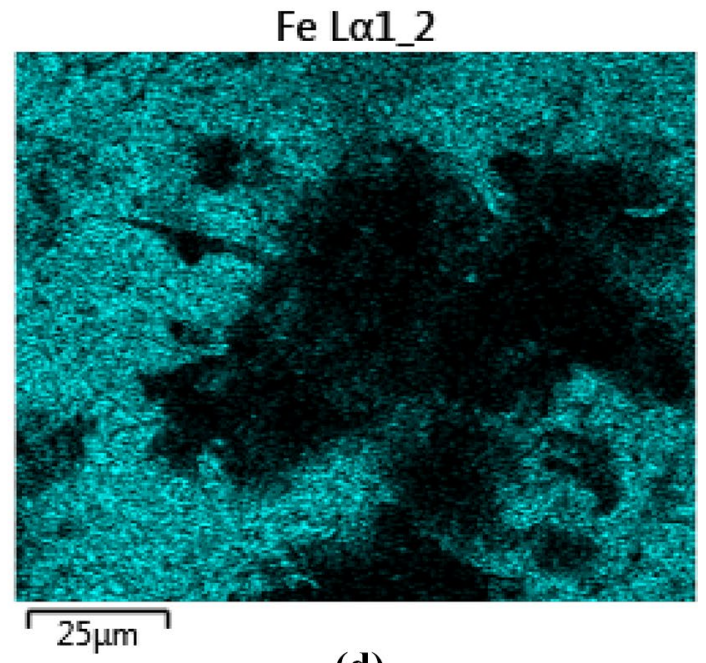

(d)

Fig. 6 EDX mapping of randomly selected punch-sheet metal contact surface ( $7.5 \mathrm{wt} \% \mathrm{SiO}_{2}$ nanolubricant)

- This study produced a lower-cost and better-performance lubricant than the commercial oils used in deep drawing processes in the industry.

- As the nanoparticle concentration in the lubricant increased, the formability also increased. However, as the nanoparticle concentration exceeded $7.5 \mathrm{wt} \%$, the formability started to decrease.

- The best $\mathrm{SiO}_{2}$ nanoparticle concentration for DC01 steel sheet was $7.5 \mathrm{wt} \%$.

- The formability of the sheet metal tested with nanolubricant increased by $13.16 \%$ compared to the specimen tested under dry conditions.
- Compared to the other oils used in the market, approximately a $12 \%$ increase was achieved in deformation depth with the $\mathrm{SiO}_{2}$ nanoparticle-added lubricant.

In general, the significant improvement in the formability of the DC01 sheet metal in our study shows that nanolubricants can lead to better tribological properties during sheet metal forming processes. In further studies, the effect of different sizes and types of nanoparticle-added lubricants on the deep drawing can be examined. In addition, the effect of the nanolubricants on different types of sheet metals will also be worthy to be researched. 


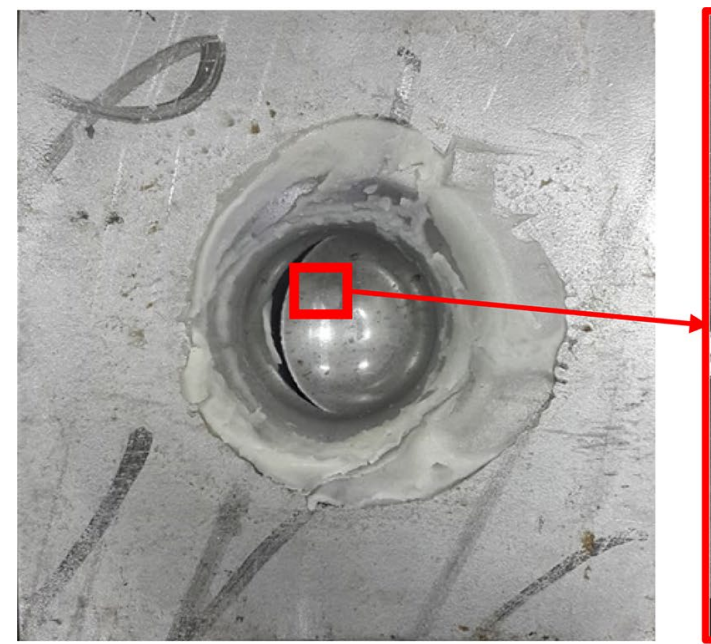

(a)

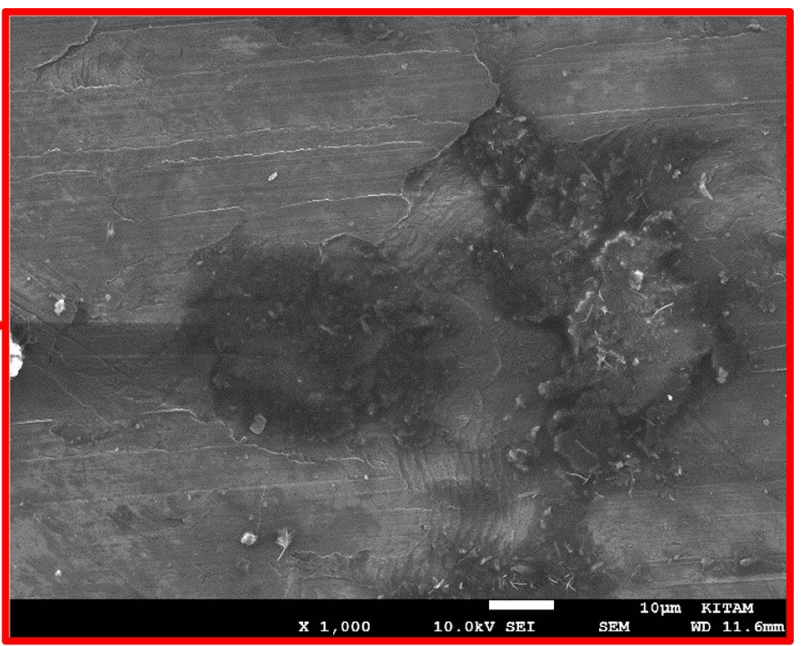

(b)

Fig. 7 a A specimen with 10 wt $\% \mathrm{SiO}_{2}$ nanolubricant after the Erichsen test; $\mathbf{b}$ a randomly selected punch-sheet metal contact surface

Si Ka1

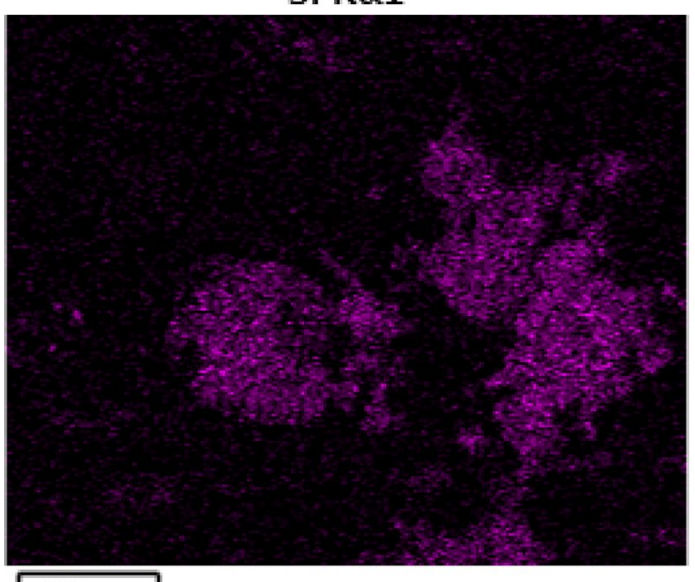

(a)

\section{Ko1_2}

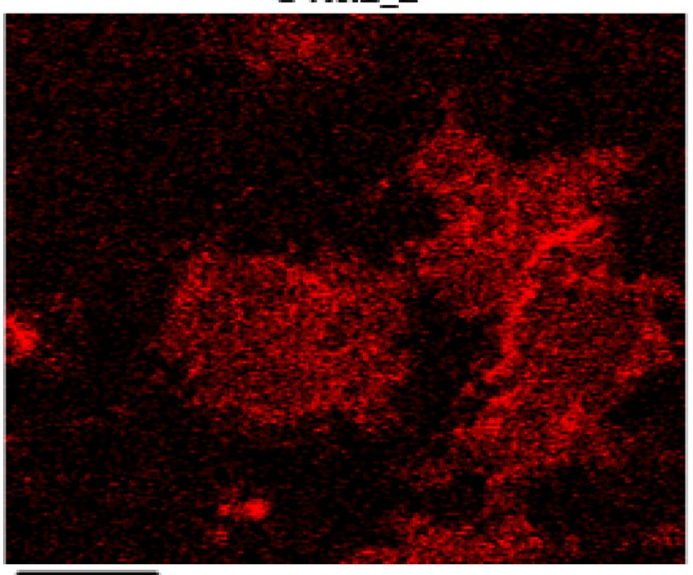

(c)

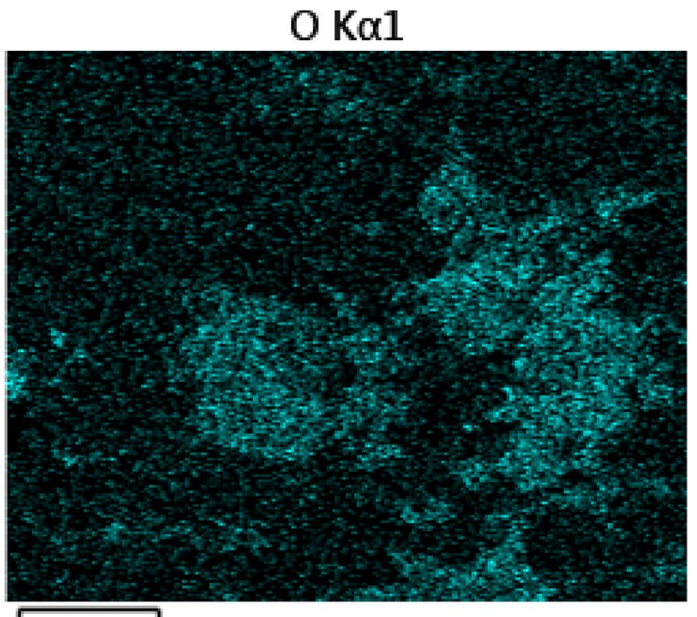

(b)

Fe L $\alpha 1 \_2$

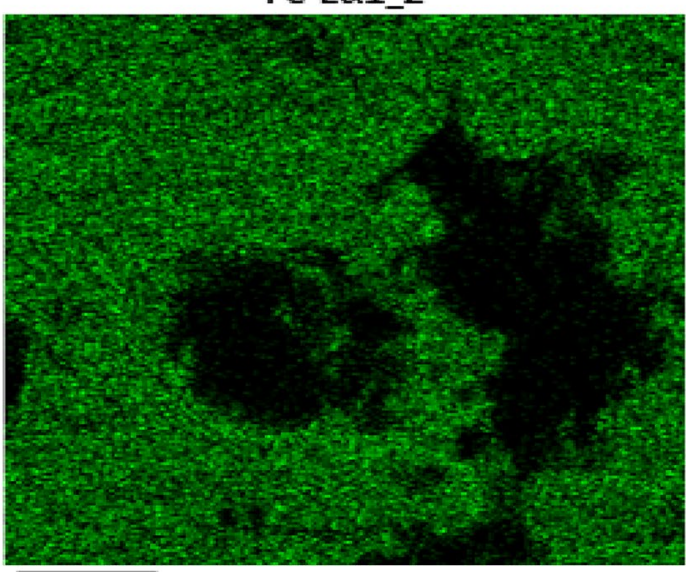

(d)

Fig. 8 EDX mapping of randomly selected punch-sheet metal contact surface ( $10 \mathrm{wt} \% \mathrm{SiO}_{2}$ nanolubricant)

\section{SN Applied Sciences}




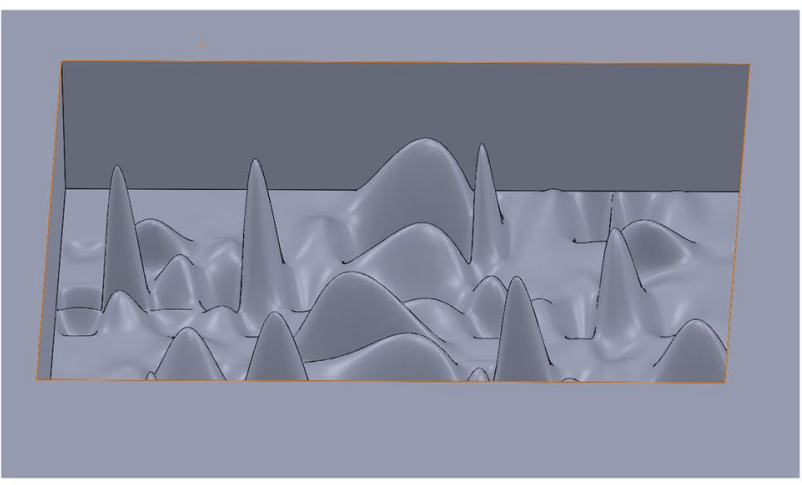

(a)

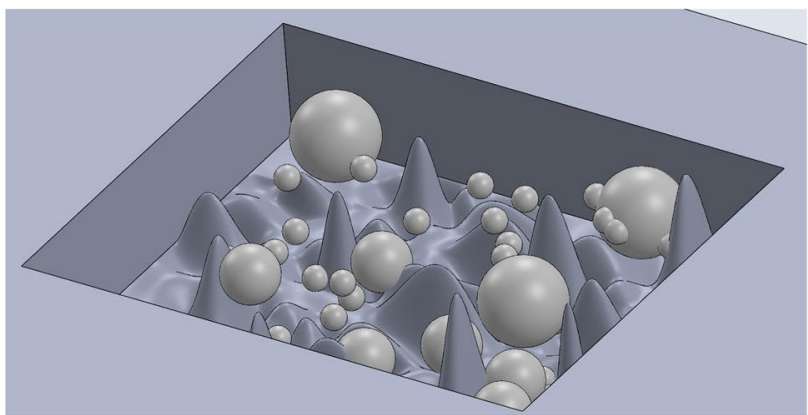

(b)

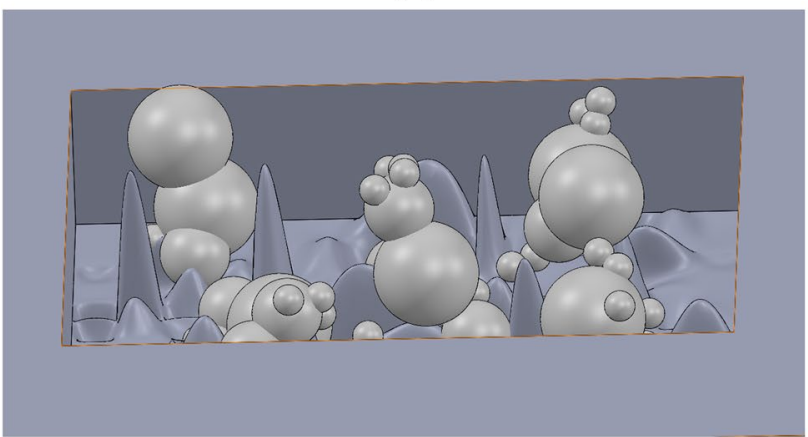

(c)

Fig. 9 Role of nanoparticles in formability. a Schematic view of roughness on sheet metal, $\mathbf{b}$ filling the valleys with nanoparticles c agglomeration of nanoparticles and occurrence of new asperities

Acknowledgements This study was financially supported by Turkish Council of Higher Education under scholar grad: ÖYP-1919-018 and TUBITAK BIDEP 2211-A. Special thanks to Cumhur Sağlam, Mechanical Engineer of SAMPA Automotive, Samsun and Cüneyt Karaca, Mechanical Engineer of AYGÜN Surgical Instruments Co., Inc., Samsun, for their collaborations in this work.

\section{Compliance with ethical standards}

Conflict of interest The authors declare that they have no conflict of interest.

\section{References}

1. Zareh-Desari B, Davoodi B (2016) Assessing the lubrication performance of vegetable oil-based nano-lubricants for environmentally conscious metal forming processes. J Clean Prod 135:1198-1209. https://doi.org/10.1016/J.JCLEPRO.2016.07.040

2. Weidel S, Engel U, Merklein M, Geiger M (2010) Basic investigations on boundary lubrication in metal forming processes by in situ observation of the real contact area. Prod Eng 4:107-114. https://doi.org/10.1007/s11740-009-0198-5

3. Mosleh M, Atnafu ND, Belk JH, Nobles OM (2009) Modification of sheet metal forming fluids with dispersed nanoparticles for improved lubrication. Wear 267:1220-1225. https://doi. org/10.1016/J.WEAR.2008.12.074

4. Li G, Long X, Yang P, Liang Z (2018) Advance on friction of stamping forming. Int J Adv Manuf Technol. https://doi.org/10.1007/ s00170-017-1538-9

5. Gulzar M, Masjuki HH, Kalam MA et al (2016) Tribological performance of nanoparticles as lubricating oil additives. J Nanoparticle Res 18:223. https://doi.org/10.1007/s11051-016-3537-4

6. Cora ÖN, Ağcayazı A, Namiki K et al (2012) Die wear in stamping of advanced high strength steels-investigations on the effects of substrate material and hard-coatings. Tribol Int 52:50-60. https://doi.org/10.1016/J.TRIBOINT.2012.02.016

7. Herrmann C, Hesselbach J, Bock R, Dettmer T (2007) Coolants made of native ester-technical, ecological and cost assessment from a life cycle perspective BT. In:Takata S, Umeda Y (eds) Advances in life cycle engineering for sustainable manufacturing businesses. Springer, London, pp 299-303

8. Chua Abdullah MIH, Bin AM, Tamaldin N et al (2016) Effect of hexagonal boron nitride nanoparticles as an additive on the extreme pressure properties of engine oil. Ind Lubr Tribol 68:441-445. https://doi.org/10.1108/ILT-10-2015-0157

9. Kim H, Sung JH, Sivakumar R, Altan T (2007) Evaluation of stamping lubricants using the deep drawing test. Int J Mach Tools Manuf 47:2120-2132. https://doi.org/10.1016/j.ijmac htools.2007.04.014

10. Kim H, Altan T, Yan Q (2009) Evaluation of stamping lubricants in forming advanced high strength steels (AHSS) using deep drawing and ironing tests. J Mater Process Technol 209:41224133. https://doi.org/10.1016/j.jmatprotec.2008.10.007

11. Bandyopadhyay K, Panda SK, Saha P, Padmanabham G (2015) Limiting drawing ratio and deep drawing behavior of dual phase steel tailor welded blanks: FE simulation and experimental validation. J Mater Process Technol 217:48-64. https ://doi.org/10.1016/j.jmatprotec.2014.10.022

12. Dengiz CG, Yıldızlı K (2017) Experimental and numerical study of process limits for deep drawing of dome-structured sheet metals. Int J Adv Manuf Technol 92:4457-4472. https://doi. org/10.1007/s00170-017-0450-7

13. Zareh-Desari B, Abaszadeh-Yakhforvazani M, Khalilpourazary $S$ (2015) The effect of nanoparticle additives on lubrication performance in deep drawing process: evaluation of forming load, friction coefficient and surface quality. Int J Precis Eng Manuf 16:929-936. https://doi.org/10.1007/s1254 1-015-0121-2

14. Gunstone $F$ (2011) Vegetable oils in food technology: composition, properties and uses. Wiley, Hoboken

15. Moser BR (2008) Influence of blending canola, palm, soybean, and sunflower oil methyl esters on fuel properties of biodiesel. Energy Fuels 22:4301-4306. https://doi.org/10.1021/ef800588x

16. Liu X, Xu N, Li W et al (2017) Exploring the effect of nanoparticle size on the tribological properties of $\mathrm{SiO}_{2} /$ polyalkylene glycol nanofluid under different lubrication conditions. Tribol Int 109:467-472. https://doi.org/10.1016/J.TRIBOINT.2017.01.007 
17. Peng DX, Kang Y, Hwang RM et al (2009) Tribological properties of diamond and $\mathrm{SiO}_{2}$ nanoparticles added in paraffin. Tribol Int 42:911-917. https://doi.org/10.1016/j.triboint.2008.12.015

18. Ding $M$, Lin B, Sui T et al (2018) The excellent anti-wear and friction reduction properties of silica nanoparticles as ceramic water lubrication additives. Ceram Int 44:14901-14906. https:// doi.org/10.1016/J.CERAMINT.2018.04.206

19. Devendiran DK, Amirtham VA (2016) A review on preparation, characterization, properties and applications of nanofluids. Renew Sustain Energy Rev 60:21-40. https://doi.org/10.1016/j. rser.2016.01.055

20. Song X, Zheng S, Zhang J et al (2012) Synthesis of monodispersed $\mathrm{ZnAl} 2 \mathrm{O} 4$ nanoparticles and their tribology properties as lubricant additives. Mater Res Bull 47:4305-4310. https://doi. org/10.1016/j.materresbull.2012.09.013

21. Rabaso P (2014) Nanoparticle-doped lubricants: potential of Inorganic Fullerene-like (IF-) molybdenum disulfide for automotive applications. Doctoral dissertation, Lyon, INSA

Publisher's Note Springer Nature remains neutral with regard to jurisdictional claims in published maps and institutional affiliations. 